Eur. J. Clin. Chem. Clin. Biochem.

Vol. 32, 1994, pp. $909-913$

(C) 1994 Walter de Gruyter \& Co. Berlin - New York

\title{
The Accuracy of Creatinine Methods Based on the Jaffé Reaction: A Questionable Matter
}

\author{
By B. G. Blijenberg and H.J. Brouwer \\ Department of Clinical Chemistry, Academic Hospital Rotterdam, Rotterdam, The Netherlands
}

(Received August 4, 1994)

Summary: The determination of creatinine in serum based on the Jaffe reaction was evaluated with four current analysers. In particular, the comparability of results was determined also with survey specimens. Recalibration of 3 out of 4 modifications was necessary, based on the results of patient samples as verified with a HPLC-method. One of the methods proved to give an unacceptable scatter for the results in the lower range $(30-150 \mu \mathrm{mol} / \mathrm{l})$.

A limited interference study (haemoglobin, lipids, bilirubin and acetone) and a method assessment with quality control sera supported the conclusion that the overall accuracy of creatinine methods based on the Jaffe reaction is questionable.

\section{Introduction}

In a previous article we described the evaluation of four state-of-the-art methods for the measurement of creatinine in serum (1). Two methods were based on the Jaffé reaction while the other two used an enzymatic approach. We conlcuded that both enzymatic procedures performed better, and that the two Jaffé methods differed in their accuracy.

Because of this study, and in view of earlier experience (2) we felt the need to check the accuracy of the creatinine determinations performed on four analysers currently used in our laboratory.

We restricted ourselves to the comparison of "around normal" samples $(30-150 \mu \mathrm{mol} / \mathrm{l})$, the calibration of the instruments and the most common interferents. We also assessed the methods by applying various quality control samples as used in the years 1992 and 1993 in the Dutch Quality Assessment Scheme (SKZL).

\section{Materials and Methods}

\section{Instrumentation}

The following instruments were used and calibrated exactly according to the instructions of the various manufacturcrs: a) Chem-1 (Bayer-Technicon, U.S. A.)

b) Hitachi 911 (Boehringer Mannheim, Germany)

c) ELAN (Merck, Germany)

d) Dimension AR (DuPont, U.S. A.)

The calibrator creatinine concentrations were as follows:
a) Chem-1:
0 and $814 \mu \mathrm{mol} / 1$ (Technicon Chem-1 SET
b) Hitachi 911: point Calibrator)
0 and $168 \mu \mathrm{mol} / 1$ (BM Calibrator for auto- mated systems)
c) ELAN:
d) Dimension:
0 and $145 \mu \mathrm{mol} / 1$ (Merck Calibrator SMT) 0,999 and $1971 \mu \mathrm{mol} / 1$ (DuPont Dimension Chem-1 Calibrator)

\section{Patient samples}

Serum samples were collected in various departments in the University Hospital Rotterdam. All samples were stored at $-70^{\circ} \mathrm{C}$ prior to use. We only used non-icteric, non-haemolytic and nonlipaemic specimens for the comparison studies. Samples were divided into two groups. Group I showed a uniform distribution of creatinine values between 40 and $150 \mu \mathrm{mol} / /$ ( 40 samples), and group II showed a uniform distribution of values 30 and $900 \mu \mathrm{mol} / \mathrm{l}$ (17 samples).

Creatinine concentrations of all samples were verified with our HPLC reference method (3).

\section{Special samples}

For the recalibration of all results we used SRM $909 a_{1}$ and $a_{2}$ Human Serum from the National Institute of Standards and Tech- 

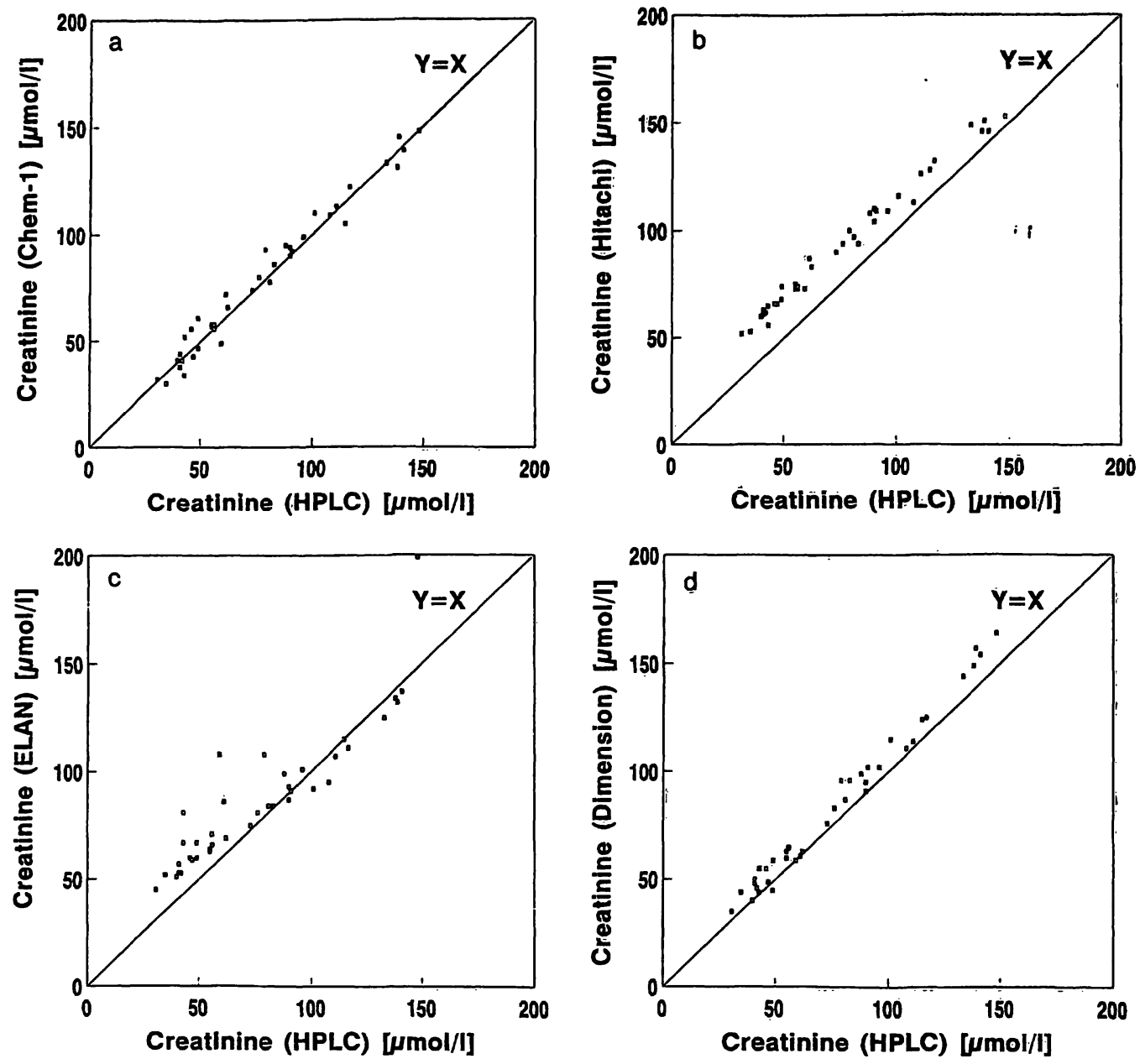

Fig. 1 Graphical presentation of the uncorrected results from patient samples obtained with the various methods.

Tab. 1 Results SRM 909 Human Serum samples

\begin{tabular}{|c|c|c|c|c|c|}
\hline \multirow[t]{2}{*}{ Sample } & \multicolumn{5}{|c|}{ Creatinine $(\mu \mathrm{mol} / \mathrm{l})$} \\
\hline & $\begin{array}{l}\text { Stated } \\
\text { value }\end{array}$ & Chem-1 & $\begin{array}{l}\text { Hitachi } \\
911\end{array}$ & ELAN & Dimension \\
\hline $\begin{array}{l}909 a_{1} \\
909 a_{2}\end{array}$ & $\begin{array}{r}84 \\
463\end{array}$ & $\begin{array}{r}90 \\
470\end{array}$ & $\begin{array}{l}104 \\
454\end{array}$ & $\begin{array}{r}97 \\
403\end{array}$ & $\begin{array}{r}84 \\
470\end{array}$ \\
\hline
\end{tabular}

Remarks:

1. Stated value $=$ value National Institute of Standards and Technology (NIST)

2. Analyser values $=$ average of $6-8$ measurements on two consecutive days

nology (Gaithersburg, U.S. A.). The samples used for the recovery study came from the Dutch Quality Assessment Foundation (SKZL). They were used in the quality control schemes in 1992 and 1993. Seven were of human origin and seven of animal origin.

\section{Interference study}

A restricted interference study was done with spiked albumin solutions as described earlier (2). We only studied the influence of haemoglobin, lipids (Intralipid $\left.{ }^{\circledR}\right)$ and acetone $(0-13.6 \mathrm{mmol} / \mathrm{l})$.

The influence of bilirubin was checked with 9 very icteric serum samples.
Tab. 2 Regression equations before and after correction

\begin{tabular}{lll}
\hline & \multicolumn{2}{l}{ Regression ëquation } \\
\cline { 2 - 3 } & Before correction & After correction \\
\hline Chem-1 & $y=1.05 x$ & $y=1.00 x-10$ \\
Hitachi 911 & $y=0.93 x+23$ & $y=1.00 x-5$ \\
ELAN & $y=0.79 x+24$ & $y=0.97 x-3$ \\
Dimension & $y=1.05 x+3$ & $y=1.02 x$ \\
\hline
\end{tabular}

Remarks:

1. Correction was done with both SRM samples

2. The graph consisted of 17 data points in the range $30-900$ $\mu \mathrm{mol} / \mathrm{l}$

3. All coefficients of correlation were at least 0.99

\section{Statistical analyses}

Regression analysis was performed according to Passing \& Bablok (4).

\section{Results}

\section{Actual situation}

All patients samples, groups I and II, were measured in duplicate together with both the SRM 909 samples. In 
Tab. 3 Interference study

\begin{tabular}{lllll}
\hline & Chem-1 & $\begin{array}{l}\text { Hitachi } \\
911\end{array}$ & ELAN & Dimension \\
\hline Haemoglobin & \pm & 0 & 0 & 0 \\
Lipids & 0 & 0 & 0 & 0 \\
Acetone & + & + & + & ++ \\
\hline
\end{tabular}

\section{Remarks:}

1. Haemoglobin: $0-10-20-50-70-100 \mu \mathrm{mol} / \mathrm{l}$

2. Lipids: Intralipid dilutions ranging from non-lipaemic to lipaemic (6 measurements)

3. Acetone: $0.0-3.4-6.8-10.2-13.6 \mathrm{mmol} / \mathrm{l}$

4. $0=$ no influence

$\pm=$ moderate influence

$+\quad=$ strong influence

$++=$ very strong influence figure 1, the results of group I samples on all four analysers are plotted against the results of our HPLC method.

\section{Calibration}

Both SRM serum samples were measured 6-8 times in total on two consecutive days. The results are given in table 1.

Using the regression lines calculated from the data in table 1, all the results of groups I and II were recalculated. Table 2 shows only the group II data, which represent a comparison between the actual (= manufacturer set) and the real (= SRM based) calibration graph.

Tab. 4 Results of all icteric serum samples

\begin{tabular}{|c|c|c|c|c|c|c|}
\hline \multirow[t]{2}{*}{ Sample } & \multirow{2}{*}{$\begin{array}{l}\text { Bilirubin } \\
(\mu \mathrm{mol} / \mathrm{l})\end{array}$} & \multicolumn{5}{|c|}{ Creatinine $(\mu \mathrm{mol} / \mathrm{l})$} \\
\hline & & HPLC & Chem-1 & Hitachi 911 & ELAN & Dimension \\
\hline 1 & 229 & 64 & 57 & 45 & 33 & 77 \\
\hline 2 & 153 & 62 & 61 & 50 & 37 & 75 \\
\hline 3 & 159 & 72 & 66 & 66 & 54 & 82 \\
\hline 4 & 191 & 101 & 86 & 85 & 69 & 116 \\
\hline 5 & 138 & 52 & 43 & 42 & 34 & 67 \\
\hline 6 & 158 & 50 & 47 & 43 & 42 & 70 \\
\hline 7 & 910 & 122 & 218 & 16 & 0 & 130 \\
\hline 8 & 124 & 60 & 48 & 49 & 41 & 74 \\
\hline 9 & 124 & 36 & 22 & 28 & 49 & 41 \\
\hline
\end{tabular}

Remarks:

1. The results were corrected with SRM 909

Recalculation of all group I results gave an improvement in accuracy.

Tab. 5 Results of all survey samples

\begin{tabular}{lrrrrr}
\hline Sample & \multicolumn{5}{l}{ Creatinine $(\mu \mathrm{mol} / \mathrm{l})$} \\
\cline { 2 - 6 } & HPLC & Chem=1 & $\begin{array}{l}\text { Hitachi } \\
911\end{array}$ & ELAN & Dimension \\
& & & & \\
\hline 1 & 74 & 72 & 86 & 75 & 67 \\
2 & 90 & 112 & 118 & 102 & 108 \\
3 & 91 & 82 & 102 & 90 & 93 \\
4 & 120 & 310 & 213 & 328 & 293 \\
5 & 70 & 48 & 71 & 65 & 57 \\
6 & 138 & 129 & 136 & 115 & 129 \\
7 & 33 & 157 & 113 & 199 & 145 \\
8 & 85 & 76 & 93 & 79 & 68 \\
9 & 56 & 207 & 142 & 221 & 179 \\
10 & 122 & 141 & 141 & 116 & 134 \\
11 & 77 & 67 & 89 & 83 & 71 \\
12 & 41 & 23 & 52 & 43 & 37 \\
13 & 134 & 162 & 159 & 134 & 161 \\
14 & 92 & 124 & 124 & 107 & 112 \\
\hline
\end{tabular}

Remarks:

1. All samples were used in surveys in The Netherlands during 1992 and 1993.

2. Samples $1,4,5,6,7,9$ and 12 were human and $2,3,8,10,11$, 13 and 14 animal

3. The results were not corrected with SRM 909

\section{Interference study}

The results of interference by haemoglobin, lipids and acetone in albumin solution (creatinine concentration $100 \mu \mathrm{mol} / \mathrm{l}$ ) are given in table 3 while the measurements of the icteric serum samples are tabulated in table 4 .

\section{Recovery}

All recovery experiments with quality control samples are described in table 5 . We only used specimens with HPLC-values between 30 and $150 \mu \mathrm{mol} / \mathrm{l}$.

\section{Discussion}

Since creatinine is important in clinical medicine, it is frustrating that the overall accuracy is still inadequate, despite all the modifications and improvements. It follows from all our evaluation work that we produce erroneous creatinine results every day. The number of errors 
is not known, but fortunately we feel that most of them will not effect patient care. However, we cannot accept the analytical errors found in our study, despite its limited design. In this respect, our study confirms the results of the study reported by Vassault et al. (5), although this was designed differently. As a multicentre survey, it described the actual situation in France with regard to creatinine determination, with the aim of proposing a selected method. No firm conclusion could be drawn, except a negative one regarding the imprecision and inaccuracy. It is clear from figure 1 in our study that three methods were calibrated wrongly (Hitachi 911, ELAN and Dimension) while one (ELAN) also showed a large scatter.

Table 1 shows the improvements after recalibration with both SRM samples. We wondered whether the results obtained after recalibration could meet objective accuracy criteria. Applying $4.4 \%(6)$ as a maximal allowable deviation in $95 \%$ of the experiments, we found that $58 \%$ of the results' for group I samples in the Chem-1 to be acceptable, for the Hitachi 55\%, for the ELAN 23\%, and for the Dimension $75 \%$. It is stressed again that all samples were taken at random from our routine production, and they showed no visible peculiarities.
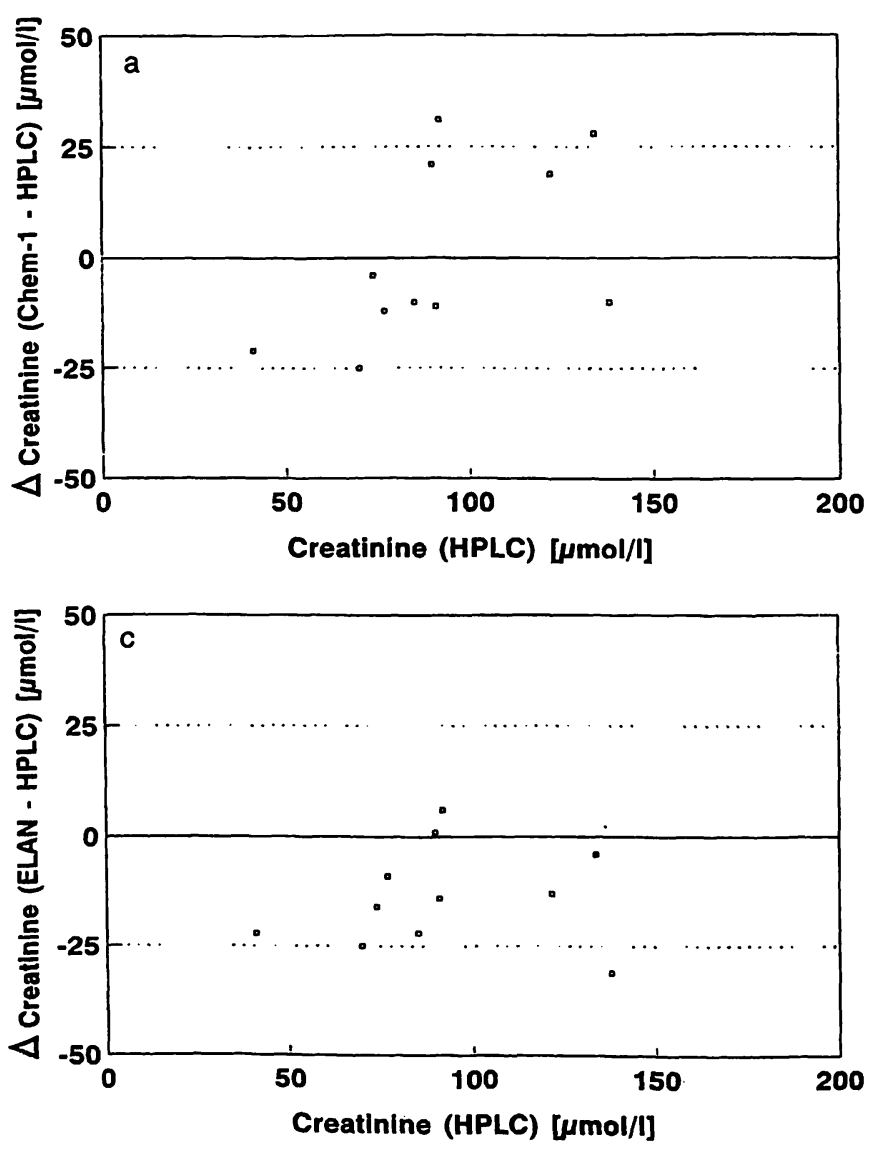

Most of the deviating results were found in the lower range ( $<60 \mu \mathrm{mol} / \mathrm{l})$ which makes all methods questionable for paediatric work.

The question arises as to what more we can expect from creatinine methods based on the Jaffe reaction. This topic has been intensively studikd by several groups (7-13), unfortunately without firm conclusions, taking into account all the interference problems that may be encountered with clinical specimens. A limited example of variability due to interference is shown in tables 3 and 4.

We therefore have to accept that there is at the moment no Jaffé modification that is completely satisfactory. There is much literature to confirm this $(14,15)$.

One solution may be the application of more specific enzymatic methods. Without doubt this would mean an improvement in accuracy, as we have also shown (1). Many laboratories changed over in the last five years from Jaffé reaction-based methods to one of the enzymatic procedures. In the Netherlands only $4 \%$ of laboratories used enzymatic methods in 1989; in 1994 this is $14 \%$ (the majority of methods being so-called dry-chemistry). German surveys show nearly $10 \%$ in 1989 and about $35 \%$ now.
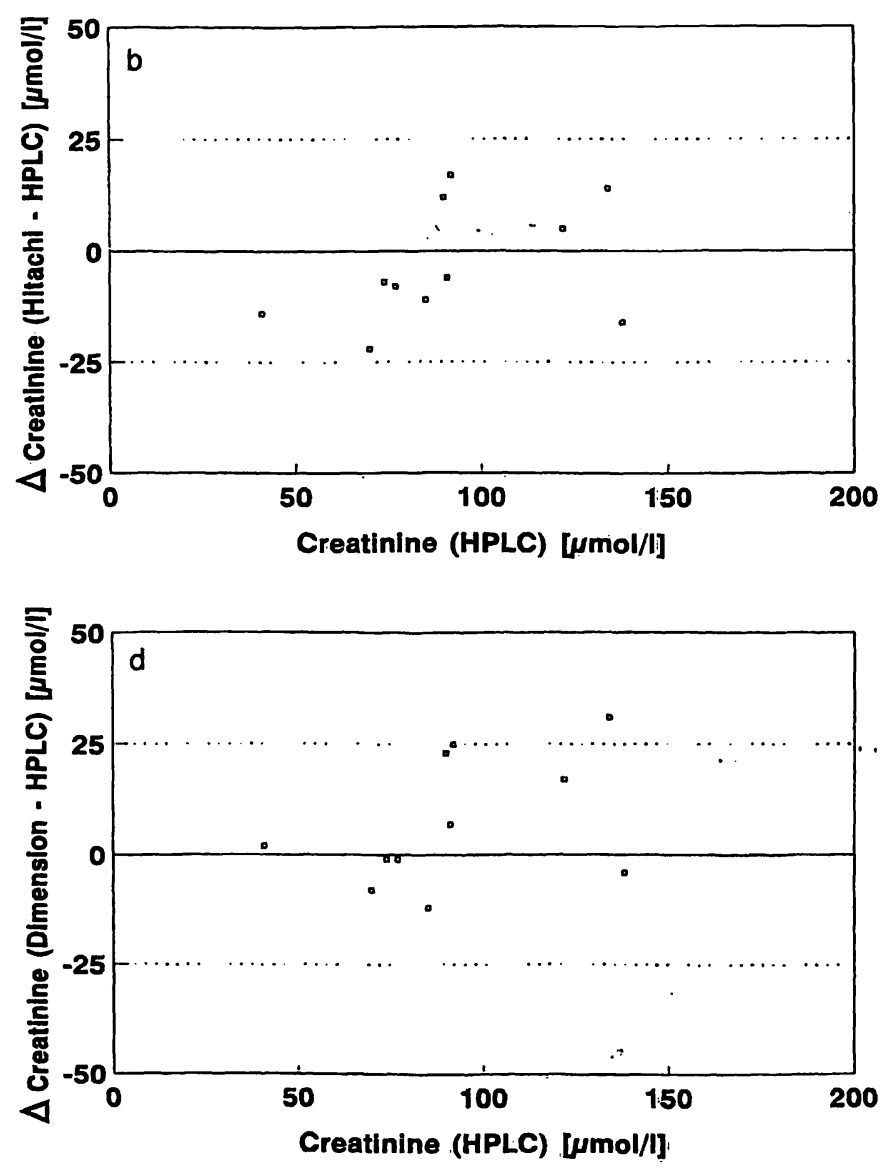

Fig. 2 Residual creatinine values (corrected) of control samples against the creatinine (HPLC) concentration for the methods under study. 
Unfortunately, enzymatic creatinine methods are also prone to interference $(1,16)$ though less than Jaffé methods. As suggested by Bacon et al. a possible solution is a combination of an enzymatic and a kinetic approach (17).

A second drawback that needs to be overcome is the high cost of enzymatic creatinine reagents.

Finally, we wish to discuss the external assessment of creatinine methods. It is clear from table 5 that only well-documented samples can be used in surveys. When the presentation of the data is redesigned and the extreme outliers are omitted (samples 4, 7 and 9) the picture presented in figure 2 still confirms this observation.

We are aware that the number of samples we used was limited. Nevertheless, it raises the question of the value of surveying the Jaffé reaction-based creatinine determination with varying control samples.

\section{References}

1. Blijenberg, B. G., Brouwer, H. J., Kuller, T., Leeneman, R. \& Leeuwen van, C. M. J. (1994) Improvements in creatinine methodology: A critical assessment. Eur. J. Clin. Chem. Clin. Biochem. 32, 529-537.

2. Blijenberg, B. G., Liesting, E. C. \& Zwang, L. (1992) Creatinine and automatic analysers in relation to icteric specimens. Eur. J. Clin. Chem. Clin. Biochem. 30, 779-784.

3. Zwang, L. \& Blijenberg, B. G. (1991) Assessment of a selected method for creatinine with special emphasis on bilirubin interference. Eur. J. Clin. Chem. Clin. Biochem. 29, 795-800.

4. Passing, H. \& Bablok, W. (1983) A new biomedical procedure for testing the equality of measurements from two different analytical methods. J. Clin. Chem. Clin. Biochem. 21, 709720.

5. Vassault, A., Cherruau, B., Labbe, D., Alabrune, B., Baltassat, P., Bonete, R., Carroger; G., Costantini, S., Georges, P., Giroud, C., Guérin; S., Honot, O., Jaffray, P., Lacour, B., Naudin, C., Nicolas, A., Thioulouse, E. \& Trepo, D. (1992) Dosage de la créatinine sérique: Résults d'une étude multicentrique de 16 systèmes analytiques. Ann. Biol. Clin. 50, 81-95.

6. Fraser, C. G., Hyltoft Petersen, P., Ricos, C. \& Haeckel, R. (1992) Proposed quality specifications for the acceptability of analytical systems for clinical chemistry. Eur. J. Clin. Chem. Clin. Biochem. 30, 311-317.

7. Bowers, L. D. (1980) Kinetic serum creatinine assays I. The role of various factors in determining specificity. Clin. Chem. $26,551-554$

8. Bowers, L. D. \& Wong, E. T. (1980) Kinetic serum creatinine assays II. A critical evaluation and review. Clin. Chem. 26, $555-561$.

9. Pardue, H. L., Bacon, B. L., Groeger Nevius, M. \& Skoug, J. W. (1987) Kinetic study of the Jaffé reaction for quantifying creatinine in serum: 1. Alkalinity controlled with $\mathrm{NaOH}$. Clin. Chem. 33, 278-285.

10. Bacon, B. L. \& Pardue, H. L. (1989) Kinetic study of the Jaffé reaction for quantifying creatinine in serum: 2 . Evaluation of
In this respect it is also worthwhile to mention the work of Kenny (18) who analysed various creatinine methods, predominantly based on the Jaffé reaction. In his effort to explain the large variation seen in surveys performed with samples spiked with interfering substances, he detected various reaction patterns.

Finally, the determination of creatinine deserves critical and constructive attention from the clinical chemical professional. However, this also holds for manufacturers. Manufacturers should be obliged to provide sufficient analytical and clinical evaluation information, at least for the most important laboratory quantities. Sometimes they do. It is, unfortunately, not common practice.

\section{Acknowledgement}

The technical help of C. J.M. van Leeuwen, H. A. Roetering and L. P. Struijk is greatly appreciated.

Thanks are due to T. Kuller for data handling support and to $A . P$. Copper-Staamer for clerical assistance.

buffered reagent and comparison of different data-processing options. Clin. Chem. 35, 360-363.

11. Llobat-Estellés, M., Sevillano-Cabera, A. \& Campins-Falcó, P. (1989) Kinetic and chemometric studies of the determination of creatinine using the Jaffé reaction. Part 1. Kinetics of the reaction: Analytical conclusions. Analyst. 114, 597-602.

12. Campins-Falcó, P., Sevillano-Cabera, A. \& Llobat-Estellés, M. (1989) Kinetic and chemometric studies of the determination of creatinine using the Jaffé reaction. Part 2. Application to human serum samples: Kinetic behaviour and chemometric evaluation of the determination. Analyst 114, 603-607.

13. Kroll, M. H., Roach, N. A., Poe, B. \& Elin, R. J. (1987) Mechanism of interference with the Jaffé reaction for creatinine. Clin. Chem. 33, 1129-1132.

14. Spencer, K. (1986) Analytical reviews in clinical biochemistry: The estimation of creatinine. Ann. Clin. Biochem. 23, 1-25.

15. Sonntag, O. (1991) Die Bestimmung der Creatinin-Konzentration in Serum und Urin: Kritische Übersicht der Routine-Bestimmungsmethoden. Dtsch. Gesell. Klin. Chem. Mitteilungen 22, 235-251.

16. Weber, J. A. \& Zanten van, A. P. (1991) Interferences in current methods for measurements of creatinine. Clin. Chem. 37, $695-700$.

17. Bacon, B. L. \& Pardue, H. L. (1991) Predictive, error-compensating kinetic method for enzymatic quantification of creatinine in serum. Clin. Chem. 37, 1338-1344.

18. Kenny, D. (1993) A study of interferences in routine methods for creatinine methods. Scand. J. Clin. Lab. Invest. 53, Suppl. $212,43-47$

Dr. B. G. Blijenberg

Academic Hospital Rotterdam

Department of Clinical Chemistry

Dr. Molewaterplein 40

NL-3015 GD Rotterdam

The Netherlands 
